\title{
Characterization of Saccharum Species Germplasm for Starch Content
}

\author{
M. M. Zhou ${ }^{1,4}$, C. A. Kimbeng ${ }^{1}$, S. J. Edme ${ }^{2}$ \& A. L. Hale ${ }^{3}$ \\ ${ }^{1}$ School of Plant, Environmental and Soil Sciences, LSU AgCenter, Baton Rouge, LA 70803, USA \\ ${ }^{2}$ USDA-ARS, Sugarcane Field Station, 12990 US Hwy 441 N, Canal Point, FL 33438, USA \\ ${ }^{3}$ Sugarcane Research Unit, ARS, USDA, Houma, LA 70360, USA \\ ${ }^{4}$ South African Sugarcane Research Institute, P. Bag X02, Mt Edgecombe 4300, South Africa \\ Correspondence: M. M. Zhou, School of Plant, Environmental and Soil Sciences, LSU AgCenter, Baton Rouge, \\ LA 70803, USA. E-mail: Marvellous.Zhou@sugar.org.za
}

Received: September 24, 2012 Accepted: October 25, 2012 Online Published: November 30, 2012

doi:10.5539/jps.v2n1p54 URL: http://dx.doi.org/10.5539/jps.v2n1p54

\begin{abstract}
The renewed interest in wild Saccharum species germplasm across sugarcane breeding programs has been necessitated by the need to widen the genetic base of breeding populations. Modern sugarcane cultivars were derived from inter-specific hybridization between $S$. officinarum and S. spontaneum. Very few genotypes were used in the initial hybridization event in 1900s resulting in narrow genetic diversity in modern sugarcane cultivars. Characterization of genotypes in the Saccharum collections would aid its utilization. Starch is considered as an impurity in sugarcane juice because it adversely affects the quantity and quality of sugar products, refining processes and is negatively associated with sucrose content. Therefore knowledge about the starch content of $S$. spontaneum and other related species would be of interest to breeders. The objective of this study was to characterize the United States of America (USA) sugarcane wild germplasm and related species for starch content. The juice samples used in this study were collected at the United State Department of Agriculture, Agricultural Research Services (USDA-ARS) Sugarcane Research Station at Houma, Louisiana; Canal Point and Miami, Florida germplasm collections. There were highly significant $(\mathrm{P}<0.001)$ differences in starch content among species and genotypes within species. There was a non-discrete distribution for starch within the species providing an opportunity for identifying low starch genotypes for use in germplasm enhancement programs. $S$. spontaneum genotypes produced the greatest variability for starch providing an opportunity for identifying low starch genotypes for use as parents. Cultivated species such as S. officinarum and S. robustum produced low starch indicating that low starch offered advantages for sucrose production. The results of this study would be more useful for parent selection within germplasm for introgression breeding.
\end{abstract}

Keywords: sugarcane, starch, introgression, S. spontaneum, S. officinarum, S. robustum

\section{Introduction}

In recent years, there has been renewed interest in wild Saccharum species germplasm across sugarcane breeding programs. The wild germplasm is being utilized to widen the genetic base of breeding populations and to tap into genes that exist in the wild species. Modern sugarcane cultivars were derived from inter-specific hybridization between two major Saccharum species, namely S. officinarum and S. spontaneum, in the early 1900s (Price, 1963). During initial sugarcane interspecific hybridization, S. officinarum was the primary source of genes for sucrose accumulation, whereas $S$. spontaneum contributed genes for high biomass, general adaptability and ratooning ability but also brought unfavorable attributes related to sugar quality (Roach, 1986). Very few Saccharum species clones have been used in the sugarcane breeding (Berding \& Roach, 1987), thereby resulting in narrow genetic diversity in modern sugarcane cultivars. Recently, there has been renewed effort to widen the genetic base using more wild Saccharum species in the germplasm introgression programs. The use of exotic germplasm for the improvement of sugarcane is an excellent example of the contributions that wild relatives of plants have made towards the genetic improvement of economically important crop species (Martin, 1996).

Efforts to broaden the genetic base while introducing novel genes to cultivated sugarcane varieties have continued to place priority on $S$. spontaneum. In Louisiana, resistance to mosaic virus was successfully transferred to $\mathrm{BC}_{4}$ progenies in cultivar x $S$. spontaneum crosses culminating in the release of LCP85-384 (Milligan et al., 1994). Despite this success, only a limited number of new $S$. spontaneum clones are represented 
in the genetic background of Louisiana cultivars. For example, all current commercially recommended varieties in Louisiana, LCP85-384, HoCP85-845, L97-128, and HoCP96-540 share the same single S. spontaneum clone, US56-15-8, in their pedigree. Although the issue of genetic diversity is being addressed, incentives that could encourage more diverse use of the $S$. spontaneum germplasm available in the collection are warranted. Characterization of clones in the collection for starch content could serve this purpose.

Sucrose yield is one of the most important traits in a commercial sugarcane breeding programs. Sucrose yield is both a function of sucrose accumulation in the plant and the ability to extract the sucrose during milling. Juice quality can affect the amount of the extracted sucrose during milling and processing. Starch is considered an impurity in sugarcane juice because it adversely affects the quantity and quality of sugar products and refining processes (Eggleston et al., 2006). In Louisiana, starch content is currently not considered as a parameter when deciding which $S$. spontaneum clones to use for germplasm enhancement, whereas $\mathrm{F}_{1}$ (commercial x $S$. spontaneum) progenies are severely penalized for low sucrose yield. Starch content in the $S$. spontaneum parent may inadvertently influence sucrose yield in the $F_{1}$ and subsequent generations, and may be responsible for the slow progress in improving sucrose content during germplasm enhancement. Knowledge about the starch content of $S$. spontaneum might be of interest to breeders seeking to use this germplasm for variety improvement in their breeding programme. S. spontaneum clones with low starch content, when used as parents, may minimize the unfavourable juice quality among the progenies.

The two landmark events in the genetic development of sugarcane were the discovery of sexual reproduction in the late $19^{\text {th }}$ century and the beneficial effects of interspecific hybridization (Berding \& Roach, 1987). The benefits of interspecific hybridization renewed sugarcane breeders' interest in the use of diverse germplasm and ended the error of collecting S. officinarum clones as the exclusive germplasm for commercial sugarcane production. This was further enhanced by the discovery of artificial induction of flowering in sugarcane in subtropical areas (Brett, 1948; Brett, 1951; Brett, 1954; Brett \& Harding, 1974; Brett et al., 1975; Moore \& Nuss, 1987). However, germplasm introgression remained limited to a few S. spontaneum clones (Arceneaux, 1967; Mangelsdorf, 1983; Price, 1967; Roach, 1972).

An understanding of the traits among germplasm and their interrelationships is important to their exploitation (Stalker, 1980). One reason for the limited use of wild germplasm was the lack of characterization of the clones in the sugarcane germplasm collections around the world (Tai \& Miller, 2002). Germplasm that has been well characterized will receive more attention in maintenance than uncharacterized germplasm (Berding and Roach, 1987) and is likely to be used in germplasm enhancements (Allison, 1984; Zhou et al., 2007). Berding and Roach (1987) concluded that germplasm characterization was an important bridge linking collection and utilization, yet these authors acknowledged that characterization has been largely ignored. Without characterization, interspecific hybridization is difficult to justify. Introgression of new germplasm is important to improve the commercial breeding populations. Also, introgression with wild germplasm is constrained by many difficulties and requires a lot of effort. Clear objectives for introgression will be enhanced by the availability of characterized germplasm. However, germplasm characterization would help identify the need for further germplasm collection to fill in the gaps and would also help reduce identification errors of clones in the collection. Characterization will allow breeders to determine the trait variability within and among species and thus guide them to the best sources of desired traits. Guidelines to characterize agricultural traits (Daniels, 1972), disease resistance (Hutchinson \& Daniels, 1972) and botany (Skinner, 1972) have been documented. However, there is little evidence of characterization at present (Berding \& Roach, 1987).

The S. spontaneum germplasm has been utilized to increase stalk numbers, yield (Roach, 1986), cold tolerance (Brandes \& Martz, 1939; Dunckelman \& Breaux, 1969) and mosaic resistance (Abbott \& Todd, 1963; Dunckelman \& Breaux, 1970). However, one of the disadvantages of S. spontaneum is low sucrose and high starch content. Starch and sucrose are storage carbohydrates in sugarcane (Artschwager \& Brandes, 1958). Starch $(\alpha-1 \rightarrow 4$-glucan), is a sugarcane juice impurity that adversely affects both factory and refinery processes and the quantity and quality of sugar products (Eggleston et al., 2006). Unfortunately, starch in sugarcane delivered for milling and processing has risen markedly in recent times because of the increased harvesting of green (unburnt) sugarcane as well as new varieties from introgression efforts (Godshall et al., 2000). Current methods for removing starch in the mills are expensive (Eggleston et al., 2003). Breeding low starch clones provides a cheaper method for reducing starch delivered to the mills. By using low starch parents, low starch progenies could be made available for selection for other agronomic and quality traits and this approach would likely lead to low starch genotypes without directly selecting for starch in the breeding program.

The important species of the Saccharum complex are S. officinarum, S. Barberi, S. sinense, S. spontaneum, S. robustum and $S$. edule. Other germplasm of immediate interest to sugarcane breeders include Erianthus, 
Ripidium, Sclerostachya, Narenga and Miscanthus (Daniels et al., 1975; Daniels \& Roach, 1987; Mukherjee, 1957). The objective of this study was to characterize the United States of America (USA) sugarcane wild germplasm and related species for starch content using collections maintained at Canal Point and Miami in Florida, and Houma in Louisiana.

\section{Materials and Methods}

The juice samples used in this study were collected at the United State Department of Agriculture, Agricultural Research Services (USDA-ARS) Sugarcane Research at Houma, Louisiana; Canal Point and Miami, Florida sugarcane germplasm collections (Table 1). At USDA-ARS Houma, the samples were collected in October 2005 from $51 S$. spontaneum clones growing in cans and one $S$. officinarum control. Another set of samples were collected from USDA-Houma from Saccharum and related species (S. barberi, S. bengalense, S. officinarum, S. robustum, S. sinense, S. spontaneum, Erianthus, and Miscanthus) in October 2005. In December 2007, juice was collected from Saccharum species (S. officinarum, S. robustum, S. spontaneum) and 6 hybrid varieties maintained at USDA-ARS, Houma, Louisiana, USA.

In Florida, all the samples were collected in December, 2007 from the Canal Point and Miami collections. Juice samples were collected from four Saccharum species (S. barberi, S. officinarum, S. sinense, S. spontaneum) and 14 hybrid varieties growing at the Canal Point nursery. Another set of samples were collected from $20 S$. spontaneum clones growing in cans at Canal Point. From the Miami collection, samples were taken from five species (S. barberi, S. edule, S. officinarum, S. robustum, and S. sinense).

Table 1. The species and dates of juice sampling at Houma in Louisiana, Canal Point and Miami in Florida, USA

\begin{tabular}{lll}
\hline Population & Species (number of clones) & Date of Sampling \\
\hline Houma - Germplasm 1 & S. spontaneum (51), S. officinarum (1) & October 2005 \\
& S. barberi (13), S. bengalense (1), & \\
Houma - Germplasm 2 & S. officinarum (9), S. robustum (11), & October 2005 \\
& S. sinense (8), S. spontaneum (5), & \\
& Erianthus (1), Miscanthus (1) & \\
& S. barberi (7), S. officinarum (1), & \\
Canal Point - Nursery & S. sinense (36), S. spontaneum (4), & December 2007 \\
& Saccharum Hybrid (14) & December 2007 \\
Canal Point - Cans & S. spontaneum (20) & \\
Miami & S. barberi (3), S. edule (1), & December 2007 \\
Houma - Racks & S. officinarum (15), S. robustum (9), S. sinense (6) \\
Replicated & S. officinarum (5), S. robustum (4), & December 2007 \\
\hline
\end{tabular}

\subsection{Sampling Methods, Juice Extraction and Starch Analysis}

At crop maturity, five stalks were randomly cut from each plot, leaves were removed and the stalks were bundled and labeled. The samples were shredded and juice was extracted in the laboratory. The brix and other quality variables were immediately measured in the laboratory. Twelve $\mathrm{ml}$ of juice was pipetted into $15 \mathrm{ml}$ tube and heated on a dry block heater for 10 minutes at $90{ }^{\circ} \mathrm{C}$. The heating was done to denature the natural amylase enzyme in the juice and stop further starch degradation. The juice was immediately cooled and stored in a $-80{ }^{\circ} \mathrm{C}$ freezer until starch analysis. Starch in juice was analyzed using the Sugar Processing Research Institute (SPRI) method (Godshall et al., 2004) used in the factory as modified by Eggleston et al. (2006). Each juice sample was divided into three sub-samples during analysis and each sub-sample was analyzed separately.

To determine starch, three $\mathrm{ml}$ of juice was transferred to three test tubes (labeled $\mathrm{A}, \mathrm{B}$, and $\mathrm{C}$ ) and covered with aluminum foil. The test tube was placed in a boiling water bath for 10 minutes to gelatinize starch. After boiling, the juice was allowed to cool on ice. To each of the sample test tubes, the following chemicals were pipetted in that order: $1.2 \mathrm{ml} 2 \mathrm{~N}$ acetic acid, $0.25 \mathrm{ml} 10 \% \mathrm{KI}$, and $2.5 \mathrm{ml} \mathrm{KIO}_{3}$. A blank tube was prepared where the $3 \mathrm{ml}$ 
juice was replaced by distilled water. The contents of the test-tubes were mixed by inverting three times. The test tubes were centrifuged to settle the solid material at the base of the test tubes. The absorbance of the samples was measured at $600 \mathrm{~nm}$ on the Shimadzu spectrophotometer. The final absorbance was calculated as the sample absorbance minus blank absorbance. The $\mu \mathrm{g}$ starch was determined directly from the calibration curve.

\subsection{Data Analysis}

The data was analyzed using SAS Institute (2008) statistical procedures. Graphs were generated using Microsoft Excel. The data from germplasm 1, germplasm 2 at Houma and Canal Point nursery (Table 1) was analyzed using the statistical linear mixed model:

$$
\mathrm{Y}_{i j k}=\mathrm{S}_{i}+\mathrm{V}(\mathrm{S})_{j(i)}+\operatorname{Sample}(\mathrm{V}(\mathrm{S}))_{k(j i))} \text {, }
$$

Equation 1

where $\mathrm{Y}_{i j k}$ is the starch content of the $k$ th sub-sample from the $j$ th variety within the $i$ th species, $\mathrm{S}_{i}$ is the fixed effect from the $i$ th species, $\mathrm{V}(\mathrm{S})_{j(i)}$ is the fixed effect from the $j$ th variety nested within the $i$ th species, Sample $(\mathrm{V}(\mathrm{S}))_{k(j i i)}$ is the random effect of the $k$ th sub-sample nested within the $j$ th variety which is in turn nested within the $i$ th species and was the residual error and was also the experimental error for the species and variety within species effect.

The samples collected from the S. spontaneum clones growing in cans at Canal Point were analyzed using the statistical linear mixed model:

$$
\mathrm{Y}_{i j}=\mathrm{V}_{i}+\text { Sample }(\mathrm{V})_{j(i)} \text {, }
$$

Equation 2

Where $\mathrm{Y}_{i j}$ is the starch content of the $j$ th sub-sample of the $i$ th variety, $\mathrm{V}_{i}$ is the effect of the $i$ th variety, sample $(\mathrm{V})_{j(i)}$ is the random effect of the $j$ th sub-sample nested within the $i$ th variety and was the residual error as well as the experimental error of the variety fixed effect.

The samples collected from the replicated species growing in pots at USDA Houma were analyzed using the statistical linear mixed model:

$$
\mathrm{Y}_{i j k m}=\mathrm{R}_{i}+\mathrm{S}_{j}+\mathrm{RS}_{i j}+\mathrm{V}(\mathrm{S})_{k(j)}+\mathrm{RV}(\mathrm{S})_{i k(j)}+\operatorname{Sample}(\mathrm{RV}(\mathrm{S}))_{m(i k(j))},
$$

Equation 3

where $\mathrm{Y}_{i j k m}$ is the starch content measured from the $m$ th sub-sample nested of the $k$ th variety, $j$ th species and $i$ th replication, $\mathrm{R}_{i}$ is the random effect of the $i$ th replication, $\mathrm{S}_{j}$ is the fixed effect of the $j$ th species, $\mathrm{RS}_{i j}$ is the random effect of the interaction of the $i$ th replication by $j$ th species and was the experimental error for the species effects, $\mathrm{V}(\mathrm{S})_{k(j)}$ is the fixed effect of the $k$ th variety nested within the $j$ th species, $\mathrm{RV}(\mathrm{S})_{i k(j)}$ is the random effect of the interaction of the $i$ th replication by the $k$ th variety nested within the $j$ th species and was the experimental error for the effect of the $k$ th variety nested within the $j$ th species, sample $(\operatorname{RV}(\mathrm{S}))_{m(i k(j))}$ is the random effect of the $m$ th sub-sample nested within the interaction of the $i$ th replication by $k$ th variety which is in turn was nested within the $j$ th species and was the residual error.

\section{Results}

\subsection{Saccharum Spontaneum at Houma}

Fifty-one $S$. spontaneum clones were analyzed for starch with one $S$. officinarum clone as a control (Table 2). The $S$. spontaneum clones produced significantly $(\mathrm{P}<0.001)$ more starch $(75 \%)$ than $S$. officinarum. There were highly significant differences $(\mathrm{P}<0.0001)$ for starch content among $S$. spontaneum clones. The frequency distribution of starch content among the S. spontaneum clones produced a non-discrete distribution (Figure 1). The clones could also be classified into low, medium and high starch content (Figure 1, Table 3). The low starch clones produced 41 to $106 \%$ starch content of the control, medium 121 to $195 \%$, and high 205 to $364 \%$. From a total of 51 clones, $10(20 \%)$ were low starch content, $26(51 \%)$ medium starch content and $15(29 \%)$ were high starch content. There were eight $S$. spontaneum clones that produced less starch content than $S$. officinarum control.

Table 2. The mean, standard deviation (Std Dev) and \% of control for starch content ( $\mathrm{ppm} /{ }^{\circ} \mathrm{Brix}$ ) for the $S$. spontaneum and $S$. officinarum control sampled at USDA, ARS Sugarcane Research Station at Houma (Zhou et al., 2008)

\begin{tabular}{lllll}
\hline Species & Number of clones & Mean & Std Dev & \% of S. officinarum \\
\hline S. officinarum & 1 & 2144.14 & 86.20 & \\
S. spontaneum & 51 & 3755.45 & 1504.24 & $175(\mathrm{P}<0.0001)$ \\
\hline
\end{tabular}


Table 3. The mean, standard deviation (Std Dev) and mean $\%$ of control for starch content (ppm/ $/{ }^{\circ}$ Brix) for $51 S$. spontaneum and $S$. officinarum control

\begin{tabular}{lllc}
\hline Clone & Mean & Std Dev & \% of control \\
\hline LA-Stripe (control) & 2144.14 & 86.20 & 100 \\
COIMBATORE & 3187.20 & 53.77 & 149 \\
DJATIROTO & 4460.69 & 143.42 & 208 \\
GUANGXI86-5 & 2088.26 & 110.77 & 97 \\
GUANGXI87-21 & 3232.88 & 131.33 & 151 \\
GUANGXI87-22 & 2602.08 & 90.16 & 121 \\
IMP9068 & 3528.80 & 65.26 & 165 \\
IMP9089 & 1836.17 & 139.54 & 86 \\
IND81-080(9775) & 1911.95 & 94.35 & 89 \\
IND81-142(9819) & 3759.09 & 83.45 & 175 \\
IND81-144(9821) & 3391.91 & 55.97 & 158 \\
IND81-161(9834) & 4560.30 & 126.78 & 213 \\
IND81-165 & 3367.99 & 104.87 & 157 \\
IND82-257A & 4406.18 & 18.20 & 205 \\
IND82-311 & 7126.05 & 0.00 & 332 \\
MPTH97-107 & 5347.42 & 391.94 & 249 \\
MPTH97-200 & 3597.98 & 391.08 & 168 \\
MPTH97-204 & 7472.47 & 95.99 & 349 \\
MPTH97-209 & 6629.05 & 991.95 & 309 \\
MPTH97-213 & 2093.38 & 91.64 & 98 \\
MPTH97-216 & 5593.66 & 157.19 & 261 \\
MPTH97-218 & 1653.97 & 69.35 & 77 \\
MPTH97-233 & 3973.14 & 205.91 & 185 \\
MPTH97-3 & 869.37 & 114.88 & 41 \\
MPTH98-388 & 3414.08 & 931.68 & 159 \\
PCA-NOR84-2A & 5272.83 & 193.86 & 246 \\
PCAV84-12A & 4835.69 & 290.45 & 226 \\
PCAV84-12B & 2646.90 & 162.90 & 123 \\
PCAV84-12C & 3376.99 & 13.96 & 157 \\
PIN84-1B & 3289.35 & 123.79 & 153 \\
PQ84-3 & 3713.47 & 86.49 & 173 \\
S66-084A & 3945.03 & 242.05 & 184 \\
S66-084B & 2242.97 & 132.53 & 105 \\
S66-121A & 4590.63 & 9.54 & 214 \\
SES-234B & 2273.11 & 404.55 & 106 \\
SES-323A & 7805.25 & 460.99 & 364 \\
SES084-58 & 3062.55 & 57.94 & 143 \\
\hline & 2674.71 & 110.17 & 125 \\
\hline
\end{tabular}




\begin{tabular}{lclc}
\hline SES147B & 1222.60 & 112.96 & 57 \\
SES189 & 3485.82 & 162.48 & 163 \\
SES205A & 3210.77 & 186.58 & 150 \\
SES231 & 4171.09 & 59.46 & 195 \\
SES234A & 4003.07 & 163.71 & 187 \\
SES234B & 4757.40 & 285.61 & 222 \\
SH249 & 5667.48 & 72.86 & 264 \\
SPONT\#17 & 3433.36 & 115.86 & 160 \\
SPONT\#24 & 1988.89 & 505.11 & 93 \\
SPONT\#37 & 4077.61 & 209.91 & 190 \\
TAINAN & 3800.54 & 10.65 & 177 \\
US56-13-7 & 4921.89 & 177.13 & 230 \\
US56-15-8 & 2928.04 & 685.42 & 137 \\
\hline
\end{tabular}

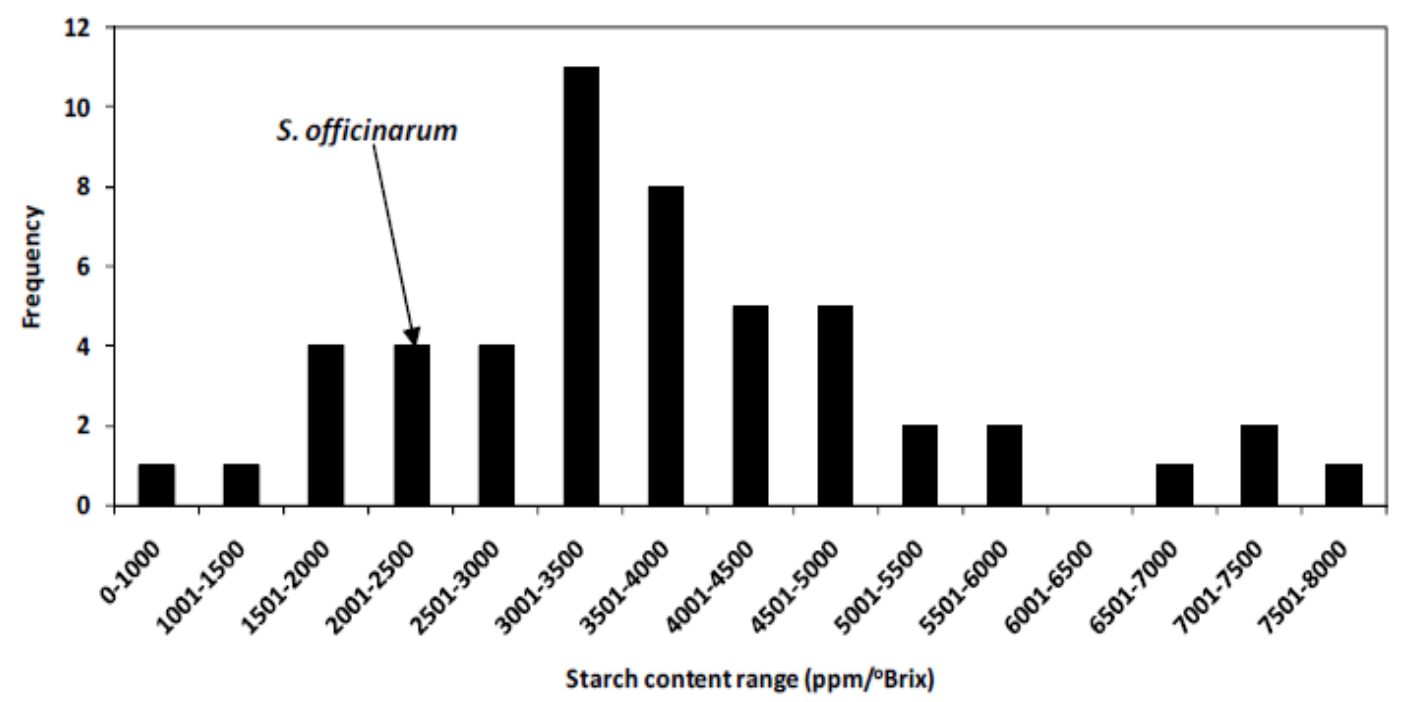

Figure 1. Frequency distribution of starch content among the S. spontaneum clones sampled from the wild species collection growing in cans at the USDA, ARS Sugarcane Research Station at Houma (Zhou et al., 2008)

\subsection{Saccharum species at USDA, ARS Sugarcane Research Station at Houma}

Samples of juice were collected from S. barberi, S. bengalense, S. officinarum, S. robustum, S. sinense, S. spontaneum, Erianthus, and Miscanthus species. There were highly significant $(\mathrm{P}<0.0001)$ differences for starch content among the species. The cultivated species (S. officinarum, S. robustum) produced significantly $(\mathrm{P}<0.05)$ less starch than their wild relatives (Table 4). Among the entries that had at least five clones, $S$. officinarum produced the lowest starch content followed by S. robustum, S. barberi and S. sinense, whereas S. spontaneum had the highest starch content. The clones from within the wild species generally produced more starch content than the cultivated species (Table 5). There were highly significant differences $(\mathrm{P}<0.0001)$ among clones within each species grouping. The $S$. spontaneum and $S$. sinense species showed the greatest within species variability for starch content (highest standard deviations) (Tables 4 and 5). The cultivated species produced lower genetic variability for starch content, probably because of selection for high sucrose (Zhou et al., 2008). 
Table 4. The mean, standard deviation (Std Dev) and mean \% of S. officinarum for starch content (ppm $\left./{ }^{\circ} \mathrm{Brix}\right)$ of the Saccharum and related species sampled at USDA, ARS Sugarcane Research Station at Houma (Zhou et al., 2007)

\begin{tabular}{lcccc}
\hline \multicolumn{1}{c}{ Species } & Number of clones & Mean & Std Dev & \% of S. officinarum \\
\hline S. barberi & 13 & 1912.96 & 243.37 & 131 \\
S. bengalense & 1 & 2580.65 & 53.45 & 176 \\
Erianthus & 1 & 2453.53 & 12.00 & 168 \\
Miscanthus & 1 & 1536.53 & 332.46 & 105 \\
S. officinarum & 9 & 1463.62 & 270.01 & 100 \\
S. robustum & 11 & 1747.58 & 423.42 & 119 \\
S. sinense & 8 & 1929.42 & 843.02 & 132 \\
S. spontaneum & 5 & 2348.57 & 846.01 & 160 \\
\hline
\end{tabular}

Table 5. The mean, standard deviation (Std Dev) and mean \% of S. officinarum for starch content (ppm/ ${ }^{\circ}$ Brix) among clones from Saccharum and related species

\begin{tabular}{llllc}
\hline Clone & Species & Mean & Std Dev & \% of S. officinarum \\
\hline CHIN & Barberi & 1760.54 & 60.94 & 120 \\
DHAULA & Barberi & 1926.81 & 27.72 & 132 \\
GANAPATHY & Barberi & 1758.25 & 63.16 & 120 \\
HATUNI & Barberi & 1984.76 & 31.30 & 136 \\
KALARI & Barberi & 1571.67 & 42.61 & 107 \\
KETARI & Barberi & 1604.87 & 21.55 & 110 \\
KHAGZI & Barberi & 2156.72 & 57.10 & 147 \\
MATNA-SHAHJ & Barberi & 2143.81 & 26.83 & 146 \\
NARGORI & Barberi & 1606.33 & 43.74 & 110 \\
NEWRA & Barberi & 2387.70 & 24.52 & 163 \\
PANURA & Barberi & 1883.32 & 50.19 & 129 \\
RENA & Barberi & 2077.51 & 55.77 & 142 \\
TERERU & Barberi & 2006.18 & 49.43 & 137 \\
IMP9751 & Bengalense & 2580.65 & 53.45 & 176 \\
NG77-214 & Erianthus & 2453.53 & 12.00 & 168 \\
MISCANTHUS-JV1 & Miscanthus & 1536.53 & 332.46 & 105 \\
BADILLA & Officinarum & 1292.19 & 13.61 & 88 \\
FIJI1 & Officinarum & 1550.54 & 46.57 & 106 \\
FIJI147 & Officinarum & 1296.49 & 24.59 & 89 \\
GREEN-GERMAN & Officinarum & 1828.41 & 28.85 & 125 \\
IN84-68A & Officinarum & 1340.77 & 8.58 & 92 \\
LA-PURPLE & Officinarum & 1999.33 & 70.22 & 137 \\
LA-STRIPE & Officinarum & 1175.68 & 42.10 & 80 \\
MENTOR-4745 & Officinarum & 1424.22 & 28.02 & 97 \\
OI-DEONG & Officinarum & 1264.88 & 21.02 & 86 \\
CHINA & Robustum & 1673.86 & 18.23 & 114 \\
CHUKCHE & Robustum & 1726.62 & 25.08 & 118 \\
\hline & & & & \\
\hline
\end{tabular}




\begin{tabular}{llllc}
\hline IMP72-232 & Robustum & 1852.21 & 17.46 & 127 \\
IS76-184 & Robustum & 2331.06 & 53.19 & 159 \\
MERTHI-ZELL & Robustum & 1601.16 & 29.35 & 109 \\
MOLOKIA & Robustum & 1303.08 & 2.88 & 89 \\
NG77-147 & Robustum & 2695.67 & 128.71 & 184 \\
NG77-159 & Robustum & 1737.24 & 28.87 & 119 \\
TUKUYU\#1 & Robustum & 1390.14 & 9.72 & 95 \\
UBA-DEL-NATAL & Robustum & 1704.65 & 27.97 & 116 \\
UBA-INDIA & Robustum & 1207.71 & 28.30 & 83 \\
IMP3057 & Sinense & 3959.17 & 509.54 & 271 \\
KATHA & Sinense & 1597.41 & 43.93 & 109 \\
MCIKUM & Sinense & 1573.70 & 20.60 & 108 \\
MERTHI & Sinense & 1156.36 & 87.04 & 79 \\
RHEA-SPORT & Sinense & 2173.15 & 81.47 & 148 \\
RUCKRI & Sinense & 1722.82 & 39.71 & 118 \\
TEKCHAOKINAWA & Sinense & 1547.88 & 49.81 & 106 \\
UBA-NAQUIN & Sinense & 1704.87 & 118.55 & 116 \\
MPTH97-260 & Spontaneum & 2356.64 & 179.71 & 161 \\
MPTH98-326 & Spontaneum & 2615.01 & 149.60 & 179 \\
MPTH99-476 & Spontaneum & 3681.71 & 70.16 & 252 \\
NG57-54 & Spontaneum & 1804.49 & 9.02 & 123 \\
SES-288 & Spontaneum & 1285.00 & 192.62 & 88 \\
\hline & & & & \\
\hline
\end{tabular}

\subsection{Replicated Germplasm at Houma}

Sixty-three clones, made up of six Saccharum hybrids, four S. officinarum, three S. robustum and $50 \mathrm{~S}$. spontaneum were grown in replicated pots at the USDA, ARS Sugarcane Research Station at Houma. There were highly significant $(\mathrm{P}<0.0001)$ differences among the hybrids and species. The hybrids produced $6 \%$ less starch content than S. officinarum while S. robustum and S. spontaneum clones produced more than double the starch content produced by $S$. officinarum (Table 6). The S. robustum and S. spontaneum produced greater within species variability as evidenced by their high standard deviations. Frequency distribution of starch content among the $S$. spontaneum clones produced a non-discrete distribution (Figure 2), similar to that of Figure 1. All the $S$. spontaneum clones produced more starch content than the $S$. officinarum clones (Table 6). The $S$. officinarum clones produced the least variability for starch content (Table 6).

Table 6. The mean, standard deviation (Std Dev) and mean \% of S. officinarum for starch content ( $\left.\mathrm{ppm} /{ }^{\circ} \mathrm{Brix}\right)$ for Saccharum hybrids, $S$. officinarum, $S$. robustum and $S$. spontaneum clones sampled from a replicated experiment growing in pots at USDA, ARS Sugarcane Research Station at Houma, Louisiana

\begin{tabular}{llllc}
\hline Species & Number of clones & Mean & Std Dev & \% of S. officinarum \\
\hline Saccharum hybrid & 6 & 788.97 & 225.48 & 94 \\
S. officinarum & 4 & 841.30 & 125.13 & 100 \\
S. robustum & 3 & 2064.08 & 582.72 & 245 \\
S. spontaneum & 50 & 2231.44 & 998.65 & 265 \\
\hline
\end{tabular}




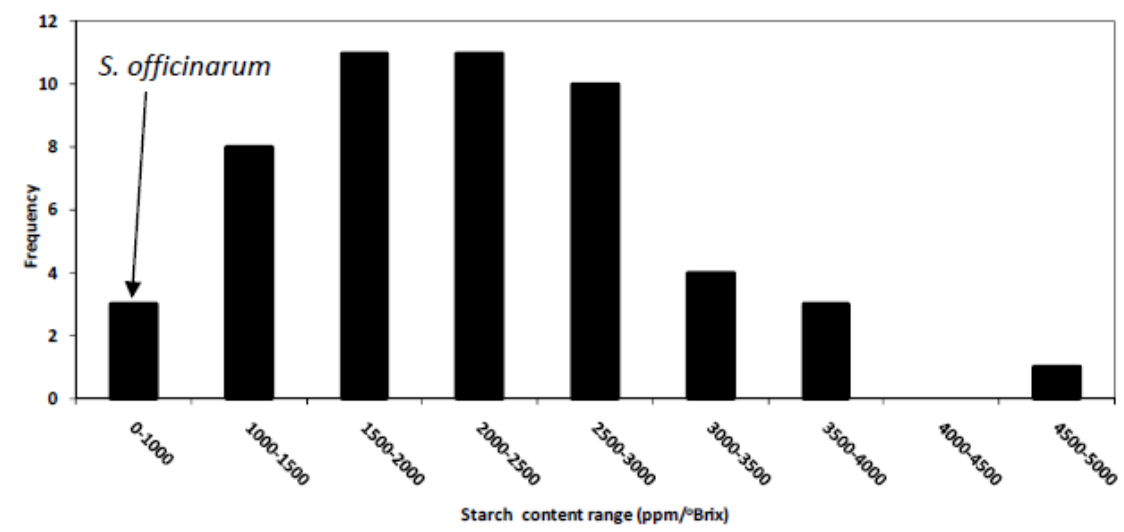

Figure 2. Frequency distribution for starch content among S. spontaneum clones sampled from a replicated experiment growing in pots at the USDA, ARS Sugarcane Research Station at Houma

\subsection{Canal Point Nursery, Florida}

At the Canal Point nursery, juice samples were collected from seven S. barberi, 14 Saccharum hybrids, 36 S. sinense, four $S$. spontaneum and one $S$. officinarum which was used as a control. There were highly significant $(\mathrm{P}<0.0001)$ differences among the species. The wild species germplasm (S. barberi, S. sinense, S. spontaneum) produced significantly $(\mathrm{P}<0.001)$ and at least three times more starch content than $S$. officinarum (Table 7$)$. The Saccharum hybrids produced two and half times more starch content than $S$. officinarum. Some of the hybrids (L01-290, L04-417, TCP89-3505) produced more than five times the amount of starch content produced by $S$. officinarum (Table 8). Other hybrids (Q158, Q160, CP02-2365) produced more than double the amount of starch content produced by $S$. officinarum.

Thirty-six $S$. sinense clones were sampled from the Canal point nursery. While the majority of the clones produced more starch content than S. officinarum and the hybrids (Tables 7 and 8, Figure 3), the $S$. sinense produced less starch content than $S$. spontaneum. The distribution of the $S$. sinense clones (Figure 4) showed that the majority of the clones produced lower starch content than $S$. spontaneum. Thirty-four out of 36 clones produced less starch content than $S$. spontaneum. The clones within the $S$. sinense population also produced a narrow variability for starch content.

Table 7. The mean, standard deviation (Std Dev) and mean $\%$ of S. officinarum for starch content ( $\left.\mathrm{ppm} /{ }^{\circ} \mathrm{Brix}\right)$ for Saccharum hybrids, S. barberi, S. officinarum, S. robustum and S. spontaneum clones sampled at Canal Point nursery, Florida

\begin{tabular}{llllc}
\hline Species & Number of clones & Mean & Std Dev & \% of S. officinarum \\
\hline S. barberi & 7 & 476.55 & 289.51 & 381 \\
Saccharum hybrids & 14 & 319.86 & 244.46 & 256 \\
S. officinarum & 1 & 124.97 & 9.28 & 100 \\
S. sinense & 36 & 380.19 & 406.67 & 304 \\
S. spontaneum & 4 & 737.01 & 340.19 & 590 \\
\hline
\end{tabular}




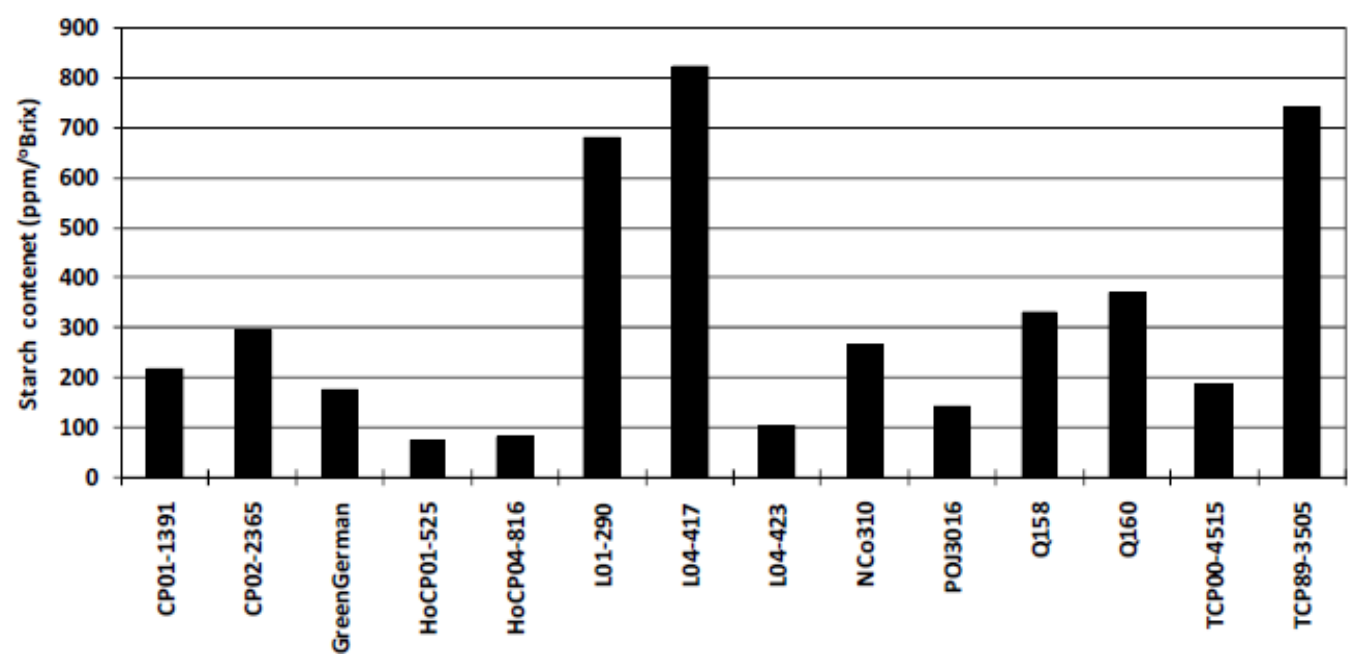

Figure 3. The mean starch content for Saccharum hybrids sampled from the Canal Point nursery, Florida

Table 8. The mean, standard deviation and mean $\%$ of $S$. officinarum for starch content (ppm $/{ }^{\circ}$ Brix) among the Saccharum species sampled at Canal Point nursery, Florida

\begin{tabular}{llllc}
\hline Variety & Species & Mean & Std Dev & \% of S. officinarum \\
\hline Grandsheni & Barberi & 318.98 & 35.19 & 255 \\
Hatooni & Barberi & 450.90 & 39.51 & 361 \\
Kalari & Barberi & 229.44 & 10.40 & 184 \\
Kinar & Barberi & 1010.98 & 11.69 & 809 \\
Lalri & Barberi & 731.88 & 16.41 & 586 \\
Mo16427 & Barberi & 449.60 & 108.89 & 360 \\
Rhea & Barberi & 144.08 & 6.75 & 115 \\
CP01-1391 & Hybrid & 216.69 & 18.98 & 173 \\
CP02-2365 & Hybrid & 294.38 & 61.67 & 236 \\
GreenGerman & Hybrid & 174.44 & 7.73 & 140 \\
HoCP01-525 & Hybrid & 74.19 & 13.32 & 59 \\
HoCP04-816 & Hybrid & 81.27 & 14.06 & 65 \\
L01-290 & Hybrid & 678.49 & 60.26 & 543 \\
L04-417 & Hybrid & 823.84 & 18.63 & 659 \\
L04-423 & Hybrid & 104.47 & 21.03 & 84 \\
NCo310 & Hybrid & 265.90 & 10.59 & 213 \\
POJ3016 & Hybrid & 142.44 & 11.07 & 114 \\
Q158 & Hybrid & 329.62 & 3.03 & 264 \\
Q160 & Hybrid & 368.29 & 0.80 & 295 \\
TCP00-4515 & Hybrid & 184.19 & 10.47 & 147 \\
TCP89-3505 & Hybrid & 739.83 & 15.77 & 592 \\
LAPurple & Officinarum & 124.97 & 9.28 & 100 \\
Agaul & Sinense & 252.85 & 7.51 & 202 \\
Archi & Sinense & 265.32 & 4.62 & 212 \\
\hline & & & & \\
\hline
\end{tabular}




\begin{tabular}{|c|c|c|c|c|}
\hline Berlin & Sinense & 369.64 & 28.73 & 296 \\
\hline China & Sinense & 329.15 & 32.44 & 263 \\
\hline Chukche & Sinense & 158.68 & 14.38 & 127 \\
\hline Chynia & Sinense & 1199.84 & 20.57 & 960 \\
\hline DesiPaunda & Sinense & 2380.33 & 8.14 & 1905 \\
\hline Guilin-1 & Sinense & 163.10 & 6.53 & 131 \\
\hline Japonesa & Sinense & 529.52 & 478.91 & 424 \\
\hline Kacai & Sinense & 228.71 & 20.54 & 183 \\
\hline Kavengire & Sinense & 689.75 & 129.60 & 552 \\
\hline Kerah & Sinense & 274.27 & 3.79 & 219 \\
\hline Ketari-II & Sinense & 394.72 & 15.00 & 316 \\
\hline Khakai & Sinense & 228.85 & 8.93 & 183 \\
\hline Louje & Sinense & 597.58 & 9.49 & 478 \\
\hline Lucane & Sinense & 651.22 & 48.61 & 521 \\
\hline Maneria & Sinense & 222.73 & 7.89 & 178 \\
\hline Mankia & Sinense & 244.63 & 5.76 & 196 \\
\hline Mcilkrum & Sinense & 128.93 & 6.65 & 103 \\
\hline Merthi & Sinense & 187.90 & 15.73 & 150 \\
\hline Merthi-Zel & Sinense & 196.62 & 3.97 & 157 \\
\hline Mialan & Sinense & 246.91 & 5.40 & 198 \\
\hline Nepal3 & Sinense & 174.19 & 19.56 & 139 \\
\hline Oshima & Sinense & 147.43 & 6.97 & 118 \\
\hline Pansahi204 & Sinense & 177.64 & 9.50 & 142 \\
\hline Sinense & Sinense & 222.49 & 7.90 & 178 \\
\hline TanzhouBamboo & Sinense & 313.52 & 0.87 & 251 \\
\hline Tekcha & Sinense & 107.89 & 6.24 & 86 \\
\hline TekchaChiisland & Sinense & 247.00 & 16.03 & 198 \\
\hline TekchaOkinawa & Sinense & 424.42 & 44.44 & 340 \\
\hline Tekchungts & Sinense & 380.95 & 21.39 & 305 \\
\hline Tukuyudist\#1 & Sinense & 201.32 & 6.11 & 161 \\
\hline UbaDelNatal & Sinense & 133.85 & 8.66 & 107 \\
\hline UbaIndia & Sinense & 251.11 & 5.06 & 201 \\
\hline UbaNaquin & Sinense & 250.58 & 11.72 & 201 \\
\hline Zwinga & Sinense & 254.17 & 10.63 & 203 \\
\hline МРТН97-3 & Spontaneum & 916.13 & 6.40 & 733 \\
\hline МРТН98-326 & Spontaneum & 287.73 & 12.23 & 230 \\
\hline МРТН98-388 & Spontaneum & 595.36 & 16.68 & 476 \\
\hline US02-1339 & Spontaneum & 1148.81 & 25.77 & 919 \\
\hline
\end{tabular}




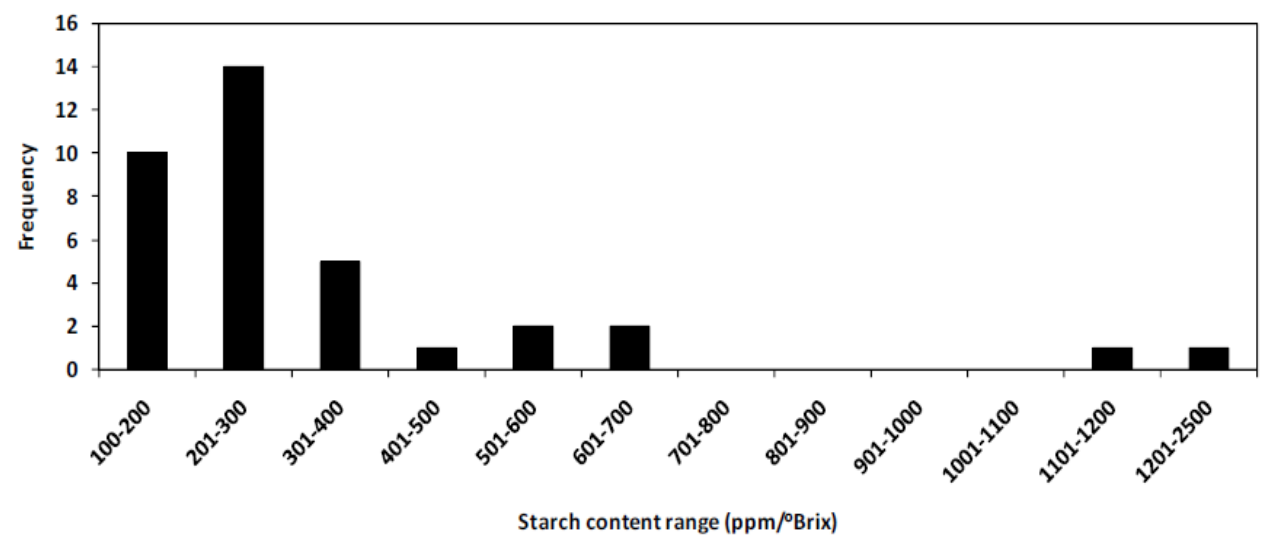

Figure 4. Frequency distribution of starch content among S. sinense clones sampled from the wild Saccharum species collection growing at Canal Point nursery, Florida

\subsection{Spontaneum Clones in Canal Point Cans, Florida}

Twenty S. spontaneum clones growing in cans were sampled at Canal Point, Florida. The frequency graph showed a non-discrete distribution for starch (Figure 5). A few clones produced extremely high starch values (Table 9, Figure 5).

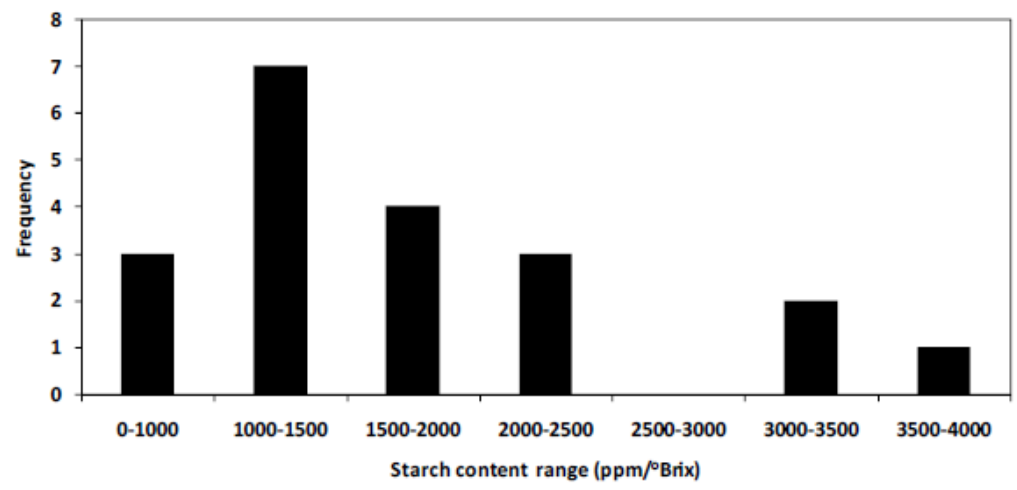

Figure 5. The distribution of starch content among 20 S. spontaneum clones growing in cans at Canal Point, Florida

Table 9. The mean and standard deviation (Std Dev) for starch content ( $\left.\mathrm{ppm} /{ }^{\circ} \mathrm{Brix}\right)$ of 20 S. spontaneum clones sampled at Canal Point, Florida

\begin{tabular}{lll}
\hline Variety & Mean & Std Dev \\
\hline Holes & 1867.92 & 89.70 \\
IN84-88 & 1160.87 & 74.18 \\
IN84-91 & 1199.94 & 213.84 \\
IND81-146 & 1035.39 & 142.41 \\
IND82-257 & 1430.31 & 684.15 \\
IND82-311 & 3900.68 & 3051.52 \\
Okinawa1 & 2054.60 & 555.49 \\
S.spont & 1029.41 & 153.01 \\
S.spont\#10 & 922.15 & 111.15 \\
\hline
\end{tabular}




\begin{tabular}{lll}
\hline S.spont\#28 & 671.18 & 567.48 \\
S.spontIran & 2564.50 & 472.33 \\
S66-121 & 879.70 & 170.20 \\
SES11 & 1329.26 & 234.31 \\
SES208 & 2146.15 & 983.93 \\
SES234 & 1128.62 & 302.83 \\
SES297A & 3229.32 & 2133.51 \\
SES92 & 3283.76 & 1838.38 \\
SLC92-51 & 1632.92 & 715.59 \\
Taiwan2n=96 & 1805.14 & 192.40 \\
US84-1058 & 1924.79 & 178.99 \\
\hline
\end{tabular}

\subsection{Miami Collection}

Juice was extracted from Four S. barberi, one S. edule, 15 S. officinarum, nine S. robustum and six S. sinense clones which were located at the wild species collection at Miami, Florida. There were highly significant $(\mathrm{P}<0.0001)$ differences among species and clones within species. The $S$. robustum clones produced more starch content that $S$. officinarum clones (Table 10). Among the S. officinarum clones, Barbados white spot and IJ76-521 clones produced much higher starch content than expected (Figure 6, Table 11).

Table 10. The mean, standard deviation (Std Dev) and mean $\%$ of S. officinarum for starch content $\left(\mathrm{ppm} /{ }^{\circ} \mathrm{Brix}\right)$ of Saccharum barberi, S. edule, S. officinarum, S. robustum and S. sinense clones sampled at Miami, Florida

\begin{tabular}{llllc}
\hline Species & Number of clones & Mean & Std Dev & \% of S. officinarum \\
\hline S. barberi & 4 & 571.59 & 300.84 & 96 \\
S. edule & 1 & 1019.26 & 27.70 & 172 \\
S. officinarum & 15 & 593.45 & 275.32 & 100 \\
S. robustum & 9 & 661.43 & 323.41 & 111 \\
S. sinense & 6 & 619.68 & 219.45 & 104 \\
\hline
\end{tabular}

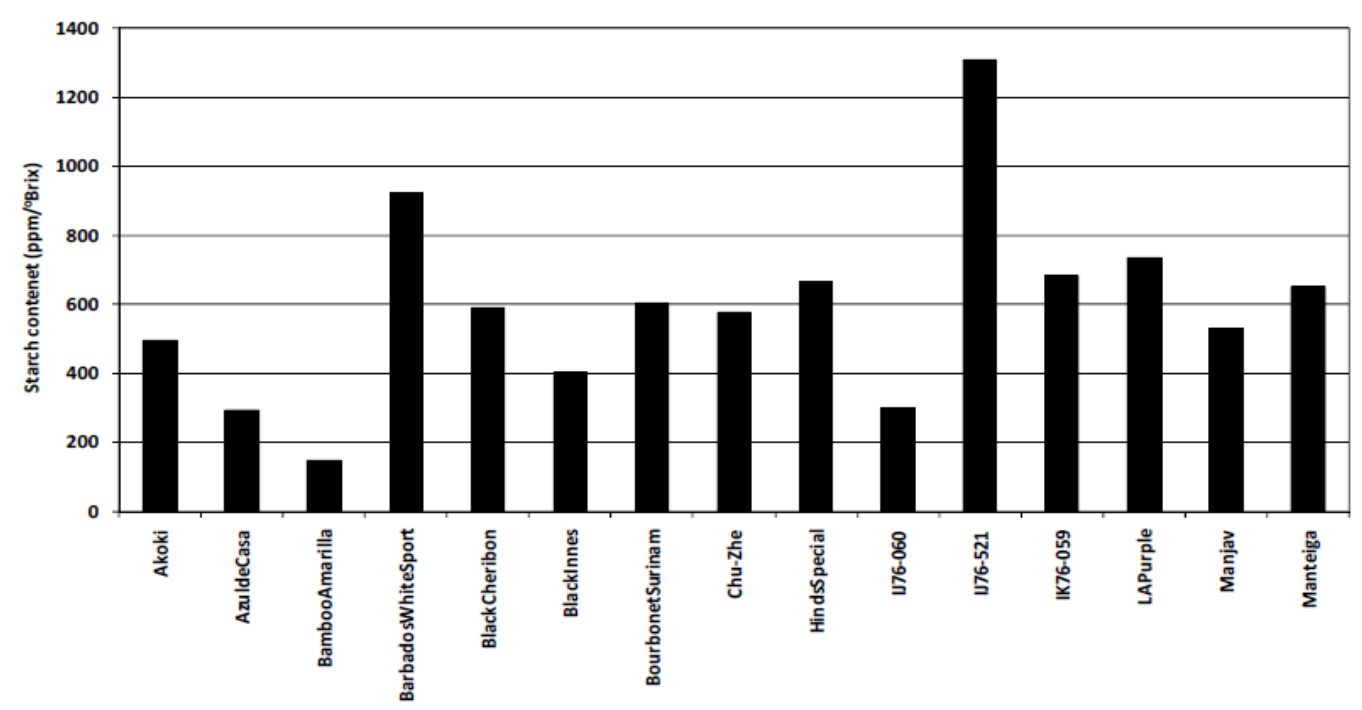

Figure 6. The mean starch content for Saccharum officinarum clones hybrids sampled from the collection at Miami, Florida 
Table 11. The mean, standard deviation (Std Dev) and mean \% S. officinarum for starch content (ppm $/{ }^{\circ}$ Brix) among the clones derived from Saccharum barberi, S. edule, S. officinarum, S. robustum and S. sinense species sampled at Canal Point nursery, Florida

\begin{tabular}{|c|c|c|c|c|}
\hline Clones & Species & Mean & Std Dev & $\%$ of $S$. officinarum \\
\hline Baroukha & Barberi & 1066.59 & 66.06 & 180 \\
\hline Kinar & Barberi & 368.75 & 1.88 & 62 \\
\hline ManeiraCoimbatore & Barberi & 429.34 & 8.71 & 72 \\
\hline Tereru & Barberi & 421.67 & 5.23 & 71 \\
\hline NG77-079 & Edule & 1019.26 & 27.70 & 172 \\
\hline Akoki & Officinarum & 495.07 & 5.35 & 83 \\
\hline AzuldeCasa & Officinarum & 293.99 & 4.63 & 50 \\
\hline BambooAmarilla & Officinarum & 146.90 & 16.56 & 25 \\
\hline BarbadosWhiteSport & Officinarum & 921.55 & 35.25 & 155 \\
\hline BlackCheribon & Officinarum & 588.78 & 3.34 & 99 \\
\hline BlackInnes & Officinarum & 402.07 & 14.01 & 68 \\
\hline BourbonetSurinam & Officinarum & 604.31 & 75.44 & 102 \\
\hline Chu-Zhe & Officinarum & 577.63 & 14.08 & 97 \\
\hline HindsSpecial & Officinarum & 666.23 & 6.56 & 112 \\
\hline IJ76-060 & Officinarum & 301.08 & 28.14 & 51 \\
\hline IJ76-521 & Officinarum & 1308.53 & 24.40 & 220 \\
\hline IK76-059 & Officinarum & 682.00 & 33.76 & 115 \\
\hline LAPurple & Officinarum & 734.80 & 17.28 & 124 \\
\hline Manjav & Officinarum & 529.08 & 8.80 & 89 \\
\hline Manteiga & Officinarum & 649.69 & 189.73 & 109 \\
\hline IJ76-424 & Robustum & 387.15 & 4.79 & 65 \\
\hline IJ76-496 & Robustum & 774.25 & 23.25 & 130 \\
\hline IJ76-547 & Robustum & 410.85 & 3.18 & 69 \\
\hline M3035/66 & Robustum & 763.06 & 16.57 & 129 \\
\hline Mol6077 & Robustum & 603.36 & 15.28 & 102 \\
\hline NG57-024 & Robustum & 509.31 & 22.21 & 86 \\
\hline NG57-054 & Robustum & 895.28 & 13.47 & 151 \\
\hline NG77-055 & Robustum & 247.69 & 27.98 & 42 \\
\hline NG77-084 & Robustum & 1361.95 & 29.83 & 229 \\
\hline DesiPaunda & Sinense & 528.26 & 14.50 & 89 \\
\hline TeckhaOkinawa & Sinense & 802.85 & 21.84 & 135 \\
\hline Tukuyudist\#1 & Sinense & 432.12 & 3.07 & 73 \\
\hline UbaDelNatal & Sinense & 998.68 & 29.55 & 168 \\
\hline UbaIndia & Sinense & 404.07 & 4.72 & 68 \\
\hline Yuegsen & Sinense & 552.08 & 9.48 & 93 \\
\hline
\end{tabular}

\section{Discussions}

This study provided the first comprehensive evaluation of starch content in a wide sugarcane germplasm collection. The results obtained in this study are expected to provide a resource to guide the selection of parental 
material for introgression programs from the wild germplasm collection. The results also provide a guide as to the variability in starch content among the Saccharum species germplasm collection. This study could also be used by other sugar industries to evaluate their collections in their environments. Additionally, sugarcane breeding programs that have similar genotypes in their germplasm collection could use the results to select the clones suitable for use in introgression programs. This would be possible because starch content was shown to be stable across environments with very little influence from genotype by environment interaction (Zhou et al., 2008).

There were non-discrete frequency distributions of starch content among the species. The non-discrete distribution implies continuous variation for starch among the wild germplasm clones particularly for $S$. spontaneum. The implication of the non-discrete distribution patterns showed that there is potential for identifying S. spontaneum clones with low starch content and such clones would desirable for germplasm introgression and enhancement programs. Clones with low starch, when used as parents in breeding programme are expected to require fewer backcross cycles with recurrent parent before they are acceptable for use in commercial breeding programs. Based on the frequency distributions, the clones could be classified into low, medium and high starch content.

This study also showed that low starch was important for successful sucrose production. The cultivated species, $S$. officinarum and S. robustum produced significantly less starch content than the wild relatives. Studies by Zhou et al. $(2007,2008)$ also showed a negative association between sucrose content and starch content in a breeding population. In this study, S. officinarum produced the lowest starch followed by S. robustum, S. barberi and $S$. sinense whereas $S$. spontaneum consistently produced the highest starch content. Our studies are in agreement with the results from a previous study by Dutt and Narasimhan (1951). The study of Dutt and Narasimhan (1951) tested 215 wild germplasm clones and cultivars and found that S. officinarum and S. robustum produced traces of starch whereas S. spontaneum, S. barberi and S. sinense accumulated much higher levels of starch.

There were highly significant differences for starch content among species and among clones within species. Selection for low starch can therefore be done at the species level as well as within the species. The data showed large variability for starch content within S. spontaneum species. S. spontaneum has been and will be used continuously for germplasm enhancement because it possesses desirable traits for hardiness, ratooning ability and high biomass production and also exhibits extensive genetic diversity because it is found in almost all continents. Studies by Alwala et al. (2006) and Suman et al. (2010) demonstrated the existence of large genetic diversity among $S$. spontaneum clones. The disadvantage of $S$. spontaneum is in its low sucrose content and high starch content. However, the large variability for starch content among clones within S. spontaneum provides an opportunity for selecting those clones that produce low starch content for use in germplasm introgression programs.

It is important to evaluate germplasm, but it is much more important to provide strategies for utilization of the germplasm. It gets difficult for plant breeders to select and add more traits in their breeding population as it complicates the selection procedure. Adding starch content as one of the selection criteria would not be a feasible option for plant breeders. We suggest that utilizing the knowledge of starch content in germplasm can be done at the crossing level. If parents with low starch content are used, the progeny produced by the introgressions are expected to produce low starch content. This study showed that there was a wide range of variation in starch content. By using low starch content parents, fewer backcrossing cycles would be required to get progeny with the desired levels of sucrose content. Conversely, if it becomes necessary to use a parent known to produce high starch content (because it possesses other desirable traits), then the breeders would be able to plan ahead the possible high number of backcrossing cycles that would be required to lower starch content in the resulting progeny populations. Previous studies by Zhou et al. $(2007,2008)$ showed that starch decreased from $F_{1}$ to $B C$, indicating backcrossing to a low starch recurrent parent would reduce the starch content.

The clones can be classified into low, medium and high starch content. Previous studies by Zhou et al. (2008) showed that the starch trait was stable across environments. These studies by Zhou et al. (2008) showed that the starch content for low starch clones was particularly more stable than that of high starch content clones. Therefore, once the parents have been characterized for starch content, the information can be used across breeding programs in different locations. The studies by Zhou et al. (2008) also showed high broad sense heritability for starch content, indicating that the genotypes within the species can be selected to identify parents that produce low starch. Furthermore, introgression programs could also be used to develop parents with low starch content, in addition to other important traits, through selection. Such developed parental genotypes would be expected to be stable for starch content across environments and would reduce the required backcrossing cycles in commercial breeding programs. 
In our study, we also compared Saccharum species hybrids. This study included the cultivar NCo310 that is known to possess high starch content (Agarwal et al., 1998). The cultivar NCo310 provided difficulties to sugar processing, particularly in South Africa, a subtropical environment. In this study, cultivars L01-290, L04-417 and TCP89-3505 were found to produce significantly higher levels of starch content than NCo310. These cultivars that produce high starch content levels could be managed in sugar cane production systems. By harvesting the cultivars towards the end of the harvesting season when their starch content has significantly decreased as suggested by Zhou et al. (2008), the impact of starch at the mill could be reduced. But late harvesting could have adverse effect on the varieties, if pest and disease pressure are taken into account. It would be beneficial for any breeding programme to incorporate low starch content in varieties via introgression breeding rather than tweaking the management practices.

\section{Conclusions}

The non-discrete frequency distributions of starch content among the species indicated that the clones could be classified for starch into low, medium and high starch content. Introgression with low starch content clones would require fewer backcrosses to the recurrent parent to eliminate the excess starch and raise the sucrose content of the progenies. Starch content was important for successful sucrose production as evidenced by the cultivated species, S. officinarum and $S$. robustum, that produced significantly less starch content than the wild relatives. The significant differences among species and among clones within species showed that selection for low starch content can be done at the species level as well as clones within the species. The large variability for starch content among clones within species particularly S. spontaneum together with the high broad sense heritability indicated that low starch content clones for use as parents can be identified. The high broad sense heritability also meant low starch content parents can be developed during introgression programs. The best strategy for utilizing the germplasm characterized for starch content is at the parent selection stage and at crossing rather than selecting for starch content as an extra trait in breeding populations. During introgression programs, starch content can be evaluated before the developed parents are recommended for the commercial breeding programs. Because starch content has been found to be stable across environments, the germplasm characterization for starch content can be applied across breeding programs. Cultivars known to produce high starch content such as NCo310, L01-290, L04-417 and TCP89-3505 can be managed by planting and harvesting in late season when starch levels are low.

\section{References}

Abbott, E. V., \& Todd, E. H. (1963). Mosaic in clones of Saccharum spontaneum. Proceedings of the International Society of Sugar Cane Technologists, 11, 753-755.

Agarwal, M., Sehtiya, H. L., \& Dendsay, J. P. S. (1998). Starch hydrolysis activity from internodes of sugarcane. Sugar Cane, 5, 16-17.

Allison, J. C. S. (1984). Use of new sugar cane germplasm. Sugar Cane, 4, 6-7.

Alwala, S., Suman, A., Arro, J. A., Veremis, J. C., \& Kimbeng, C. A. (2006). Target Region Amplification Polymorphism (TRAP) for Assessing Genetic Diversity in Sugarcane Germplasm Collections. Crop Science, 46, 448-455. http://dx.doi.org/10.2135/cropsci2005.0274

Arceneaux, G. (1967). Cultivated sugarcanes of the world and their botanical derivation. Proceedings of the International Society of Sugar Cane Technologists, 12, 844-854.

Artschwager, E., \& Brandes, E. W. (1958). Sugarcane (Saccharum officinarum L.): Origin, classification, characteristics and descriptions of representative clones. USDA Agriculture Handbook 122. US Government Print Office, Washington, DC.

Berding, N., \& Roach, B. T. (1987). Germplasm collection, maintenance and use. In D. J. Heinz (Ed.). Sugarcane Improvement Through Breeding. pp. 143-210. Elsevier, New York.

Brandes, E. W., \& Martz, J. (1939). Problems and progress in breeding temperate zone sugarcane. Sugar Journal, 2, 3-6.

Brett, P. G. C. (1948). Seed setting of sugar cane in South Africa. Nature, 157, 657-658. http://dx.doi.org/10.1038/157657c0

Brett, P. G. C. (1951). Flowering and pollen fertility in relation to sugarcane breeding in Natal. Proceedings of the International Society of Sugar Cane Technologists, 7, 43-56.

Brett, P. G. C. (1954). Saccharum - Miscanthidium hybrids. Journal of Genetics, 52, 542-546. http://dx.doi.org/10.1007/BF02985077 
Brett, P. G. C., \& Harding, R. (1974). Artificial induction of flowering in Natal. Proceedings of the International Society of Sugar Cane Technologists, 15, 55-66.

Brett, P. G. C., Harding, R., \& Paxton, J. G. (1975). Time and intensity of flowering as influenced by certain temperature and photoperiod treatments. Proceedings of the South African Sugar Technologists Association, $49,202-205$.

Daniels, J. (1972). Description of sugarcane clones. I. Agricultural description. Proceedings of the International Society of Sugar Cane Technologists, 14, 112-119.

Daniels, J., Smith, P., Paton, N. H., \& Williams, C. A. (1975). The origin of the genus Saccharum. Sugarcane Breeders Newsletter, 36, 24-39.

Daniels, J., \& Roach, B. T. (1987). Taxonomy and evolution. In D. J. Heinz (Ed.). Sugarcane Improvement Through Breeding. pp.7-84. Elsevier.

Dunckelman, P. H., \& Breaux, R. D. (1969). Agronomic characteristics of S. spontaneum clones in culture at Houma, Louisiana. International Sugar Journal, 71, 333-334.

Dunckelman, P. H., \& Breaux, R. D. (1970). New sugarcane breeding clones from Indian crosses evaluated at Houma, Louisiana, 1966-1969. International Sugar Journal, 72, 43-44.

Dutt, N. L., \& Narasimhan, R. (1951). Starch in the genus Saccharum and interspecific and intergeneric hybrids. Proceedings of the Sugarcane Research Workers in the Indian Union, 1, 4-10.

Eggleston, G., Monge, A., \& Ogier, B. (2003). Sugarcane factory performance of cold, intermediate, and hot lime clarification systems. Journal of Food Processing and Preservation, 26(6), 433-454. http://dx.doi.org/10.1111/j.1745-4549.2003.tb00864.x

Eggleston, G., Montes, B., Monge, A., \& Guidry, D. (2006). Optimization of $\alpha$-amylase application in raw sugar manufacture. Proceedings of the Sugar Processing Research Conference, Brazil, 319-340.

Godshall, M. A., Legendre, B. L., Richard, C., \& Triche, R. (2000). Effect of harvest system on cane juice quality. Proceedings of the Sugar Processing Research Conference, Portugal, pp. 222-236.

Godshall, M. A., Triche, R., \& Moore, S. J. (2004). Collaborative study on starch in raw sugar using SPRI rapid starch method. Proceedings of the Sugar Processing Research Conference, Atlanta Georgia, USA, pp. 442-448.

Hutchinson, P. B., \& Daniels, J. (1972). Description of sugarcane clones. II. Genetical and disease resistance information. Proceedings of the International Society of Sugar Cane Technologists, 14, 120-123.

Mangelsdorf, A. J. (1983). Cytoplasmic diversity in relation to pests and pathogens. Sugarcane Breeders Newsletter, 45, 45-49.

Martin, F. A. (1996). Survey of germplasm needs for Saccharum species in the United States. Louisiana Agricultural Experiment Station. Retrieved from http://www.ars-grin.gov/nggs/cgc_reports/ sugar.html

Milligan, S. B., Martin, F. A., Bischoff, K. P., Quebedeaux, J. P., Dufrene, E. O., Quebedeaux, K. L., ... Miller, J. D. (1994). Registration of 'LCP 85-384' sugarcane. Crop Sci., 34, 819-820. http://dx.doi.org/10.2135/cropsci1994.0011183X003400030042x

Moore, P. H., \& Nuss, K. J. (1987). Flowering and flower synchronization. In D. J. Heinz (Ed.). Sugarcane Improvement Through Breeding. pp. 273-311. Elsevier.

Mukherjee, S. K. (1957). Origin and distribution of Saccharum. Botany Gazette, 119, 55-61. http://dx.doi.org/10.1086/335962

Price, S. (1963). Cytogenetics of modern sugarcanes. Economic Botany, 17, 97-105. http://dx.doi.org/10.1007/BF02985359

Price, S. (1967). Interspecific hybridization in sugarcane breeding. Proceedings of the International Society of Sugar Cane Technologists, 12, 1021-1026.

Roach, B. T. (1972). Nobilization of sugarcane. Proceedings of the International Society of Sugar Cane Technologists, 14, 206-216.

Roach, B. T. (1986). Evaluation and use of sugarcane germplasm. Proceedings of the International Society of Sugar Cane Technologists, 16, 492-503.

SAS Institute. (2008). SAS/STAT user's guide, version 9.1.3. SAS Institute, Cary, North Carolina, USA. 
Skinner, J. C. (1972). Description of sugarcane clones. 3. Botanical description. Proceedings of the International Society of Sugar Cane Technologists, 14, 124-127.

Stalker, H. T. (1980). Utilization of wild species for crop improvement. Advances in Agronomy, 33, 111-147. http://dx.doi.org/10.1016/S0065-2113(08)60165-0

Suman, A., Kimbeng, C. A., Edmé, S. J., \& Veremis, J. C. (2010). Sequence-related amplified polymorphism (SRAP) markers for assessing genetic relationships and diversity in sugarcane germplasm collections. Plant Genetic Resources: Characterization and Utilization, 6(23), 215-221.

Tai, P. Y. P., \& Miller, J. D. (2002). Germplasm diversity among four sugarcane species for sugar composition. Crop Science, 42, 958-964. http://dx.doi.org/10.2135/cropsci2002.0958

Zhou, M., Kimbeng, C. A., Eggleston, G., Veremis, J. C., \& Gravois, K. A. (2007). Prospects of breeding for low starch content in sugarcane. Proceedings of the International Society of Sugar Cane Technologists, 26, 724-729.

Zhou, M. M., Kimbeng, C. A., Eggleston, G., Viator, R. P., Hale, A. L., \& Gravois, K. A. (2008). Issues of Starch in Sugarcane Processing and Prospects of Breeding for Low Starch Content in Sugarcane. Sugarcane International, 26(3), 3-12. 